Résumés des conférences et travaux

\title{
Paul Garelli (1924-2006)
}

Nécrologie

Dominique Charpin

\section{(2) OpenEdition}

\section{Journals}

Édition électronique

URL : https://journals.openedition.org/ashp/163

DOI : 10.4000/ashp.163

ISSN : 1969-6310

Éditeur

Publications de l'École Pratique des Hautes Études

\section{Édition imprimée}

Date de publication : 1 octobre 2008

Pagination : XVII

ISSN : 0766-0677

\section{Référence électronique}

Dominique Charpin, «Paul Garelli (1924-2006) », Annuaire de l'École pratique des hautes études (EPHE), Section des sciences historiques et philologiques [En ligne], 139 | 2008, mis en ligne le 08 juillet 2008, consulté le 12 juillet 2021. URL : http://journals.openedition.org/ashp/163 ; DOI : https://doi.org/ 10.4000/ashp.163

Ce document a été généré automatiquement le 12 juillet 2021.

Tous droits réservés : EPHE 


\section{Paul Garelli (1924-2006)}

\section{Nécrologie}

\section{Dominique Charpin}

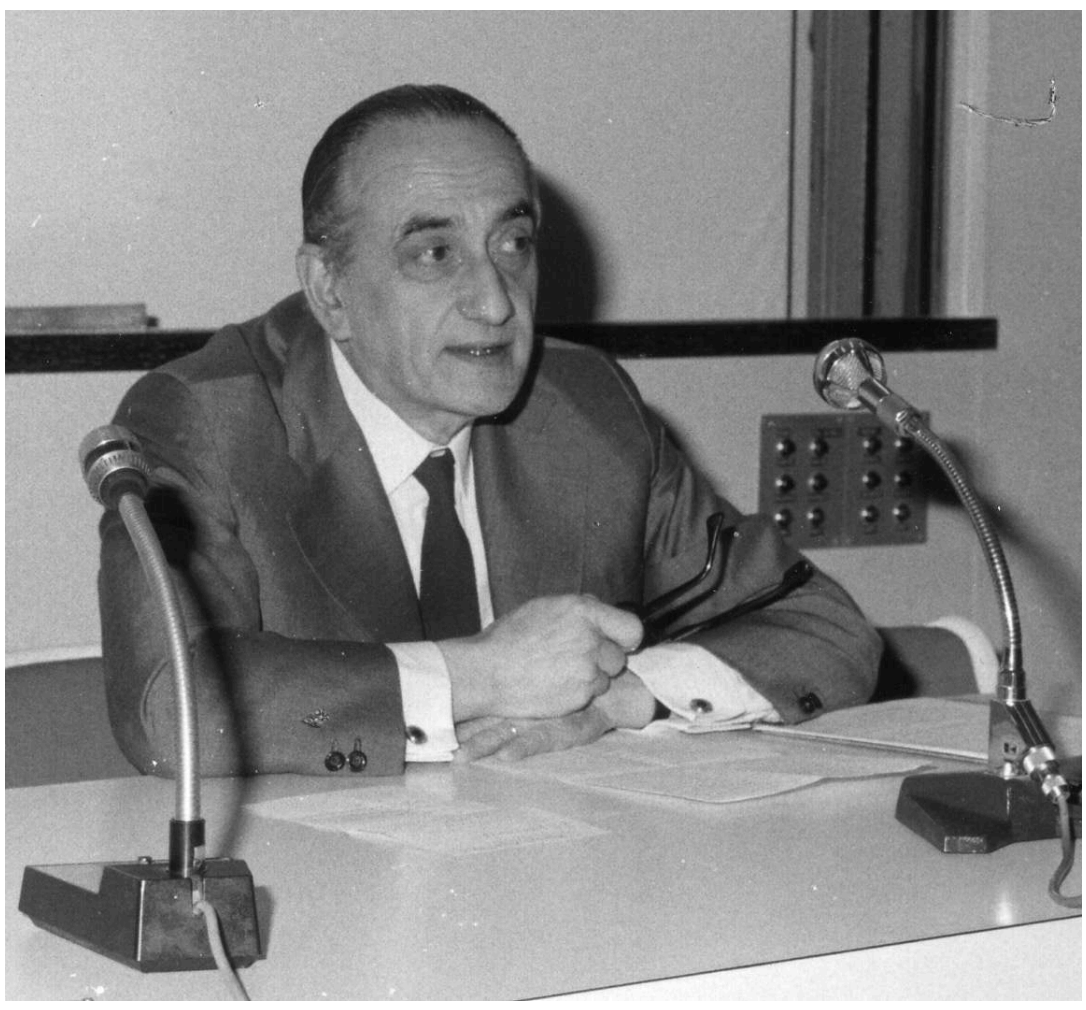

Cliché : Institut d'assyriologie du Collège de France

1 Paul Garelli nous a quittés le 8 juillet 2006, après plusieurs années d'éloignement, puisque sa santé l'avait contraint à résider à Nice, auprès d'une de ses filles; il était dans sa quatre-vingt-troisième année.

2 Paul Garelli eut au début de sa vie une existence cosmopolite. Né à Londres d'un père français d'origine corse et d'une mère suisse, il vécut son enfance en Yougoslavie, puis à Istanbul; lors de sa leçon inaugurale au Collège de France, il évoqua de façon 
émouvante l'amour de l'Orient que son père lui inculqua et qui devait infléchir le cours de son existence. Au départ, ce fils de banquier songea à une carrière commerciale et il obtint en 1944 sa licence en sciences économiques à l'université de Genève et peu après une licence d'histoire. En 1946, il partit pour Paris et c'est là que l'École pratique joua un rôle décisif : il y suivit les enseignements d'hébreu et de hittite, alors donnés par Dhorme et Laroche à la $\mathrm{V}^{\text {e }}$ Section, ainsi que ceux d'assyrien et de sumérien que dispensaient Labat et Jestin à la IV Section. En 1951, il devint élève diplômé de notre Section avec un travail sur le mythe du Lugal-e. Cependant, l'édition de textes littéraires sumériens ne correspondait pas vraiment à ses goûts; l'enthousiasme communicatif d'Emmanuel Laroche lui fit songer un moment à poursuivre en hittite. C'est alors que René Labat, qui l'accueillit comme collaborateur au Collège de France, lui proposa de se spécialiser dans l'étude des archives des marchands assyriens de Cappadoce. Ainsi Paul Garelli put-il combiner son attrait pour l'Anatolie et son intérêt pour l'histoire économique. En 1958, il entra au CNRS; il y acheva la préparation de son doctorat ès lettres. Sa "petite thèse " consista en l'édition de plusieurs dizaines de tablettes issues des archives des marchands assyriens installés au cœur de l'Anatolie au $\mathrm{XIX}^{\mathrm{e}}$ siècle avant notre ère, conservées dans différentes collections publiques ou privées: le cas le plus curieux est celui d'une tablette ramassée sur une dune de l'île d'Aix, en Charente-Maritime. Comme l'écrivit Paul Garelli, non sans humour : « Devant une découverte aussi insolite, il serait tentant de rêver à l'extension du commerce cappadocien, ou aux migrations des Galates, mais de telles disquisitions risqueraient fort de n'entraîner qu'une adhésion limitée » (RA, 60 [1966], p. 142). Sa "grande thèse » aboutit à la première synthèse consacrée aux Assyriens en Cappadoce. Elle fut publiée par Louis Robert dans la "Bibliothèque archéologique et historique de l'Institut français d'Istanbul» en 1963. Ce travail se voulait une mise au point, d'autant plus nécessaire que les études portant sur les archives de ces commerçants assyriens étaient très ponctuelles : ce qui frappe dans ce livre, c'est bien l'ampleur de vue d'un véritable historien, chose alors exceptionnelle dans le monde des assyriologues, dominé par des philologues dont la myopie était au même moment dénoncée par Oppenheim, qui prônait de son côté une approche anthropologique. Les choses ont heureusement bien changé et Paul Garelli a joué un rôle important dans cette transformation.

André Dupont-Sommer étant devenu professeur au Collège de France, Paul Garelli lui succéda à la Sorbonne en octobre 1967 comme maitre de conférences, puis professeur titulaire en novembre 1969. Il vécut les déchirements de la partition de la Sorbonne et, entraîné par Hélène Arweilher, il opta pour Paris 1. Cette université avait à ses yeux l'attrait de réunir notamment historiens, juristes et économistes, ce qui laissait augurer de fructueuses études pluri-disciplinaires ; malheureusement, il ne put convaincre le titulaire de la chaire l'Égyptologie de suivre le même chemin. L'enseignement de Paul Garelli à Paris 1 a permis aux étudiants intéressés par l'Antiquité de découvrir qu'avant les Grecs et les Romains, d'autres peuples, en Orient, avaient laissé une documentation considérable; c'est ainsi qu'il a pu attirer ceux qui forment aujourd'hui la relève en assyriologie.

4 À la mort de René Labat, en 1974, il fut élu directeur d'études cumulant par notre Section; il devait y enseigner pendant vingt ans. Dans le «Projet d'enseignement d'assyrien" qu'il soumit alors, il écrivait: "Ma collaboration avec M. Bottéro faciliterait le développement de la recherche assyriologique, car son œuvre porte plus que la mienne sur les courants d'idées et la Babylonie. Je me suis plutôt penché sur l'histoire de l'Assyrie et l'analyse des structures politiques, économiques et sociales. » 
Entraîné par Jean-Marie Durand, qui était alors son assistant à Paris $1, \mathrm{j}$ 'ai suivi cet enseignement dès la première année, alors que j'étais étudiant en maîtrise. Et je puis témoigner que Paul Garelli a tenu parole, lui qui avait annoncé : «Épigraphiste, j’ai publié un grand nombre de tablettes inédites et j'estime nécessaire que les jeunes chercheurs soient d'abord des épigraphistes. » Lors de ses conférences, on travaillait directement sur des copies des textes cunéiformes, jamais sur des transcriptions : cela découragea quelques-uns, mais permit aux autres de bien se former.

La suite de sa brillante carrière est connue : il fut élu membre ordinaire de l'Académie des inscriptions et belles-lettres en février 1982 et devint professeur au Collège de France en 1986. Ses responsabilités furent nombreuses. Je me limiterai aux plus importantes. À la mort de Jean Nougayrol, en 1975, il devint l'un des deux directeurs de la Revue d'assyriologie. La même année, Georges Dossin lui transmit la présidence du Groupe Thureau-Dangin, qui patronnait alors les Rencontres assyriologiques internationales, qui se tiennent chaque année en juillet dans une ville différente et jouent un rôle très important pour promouvoir la coopération internationale dans notre domaine; il avait déjà édité les actes de la Rencontre de 1958, consacrée à Gilgamesh et sa légende, et de celle de 1971, sur le thème central en assyriologie : le Palais et la royauté.

6 Paul Garelli laisse une œuvre importante: sept livres dont un encore à paraître, et plus de soixante-dix articles ou contributions à des ouvrages collectifs. Son rayonnement international fut considérable. C'est ainsi que Paolo Matthiae fit appel à lui pour participer au comité international parrainant l'édition des textes découverts en Syrie à Ebla. De même Kirk Grayson lui demanda d'être membre de l'Editorial Board du projet «Royal Inscriptions of Mesopotamia» de l'université de Toronto. Enfin, il eut le bonheur de se voir confier par Tahsin Özgüç la publication d'un lot d'archives découvert en 1990 dans les ruines du quartier occupé par les marchands assyriens sur le site de Kültépé/Kaneš.

7 Paul Garelli était un homme très apprécié pour sa modération et son sens des valeurs humaines; sa famille compta beaucoup pour lui et il eut pendant des années à aider sa femme à supporter une longue et pénible maladie, ce qu'il fit avec une abnégation remarquable. Avec son départ, la génération des assyriologues qu'il a formés se sent orpheline.

\section{INDEX}

Thèmes : Nécrologies 
AUTEUR

DOMINIQUE CHARPIN

Directeur d'études, École pratique des hautes études - Section des sciences historiques et philologiques. 